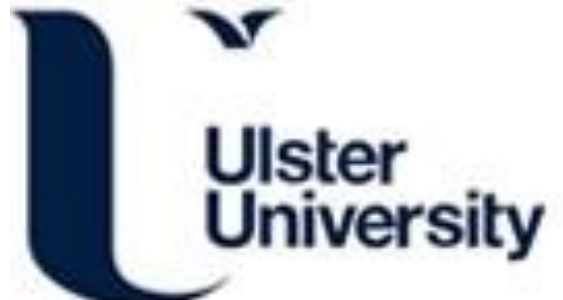

\section{Destruction of chemical warfare surrogates using a portable atmospheric pressure plasma jet}

Škoro, N., Puač, N., Živković, S., Krstić Milošević, D., Cvelbar, U., Malović, G., \& Petrović, Z. (2018). Destruction of chemical warfare surrogates using a portable atmospheric pressure plasma jet. European Physical Journal D: Atomic, Molecular, Optical and Plasma Physics, 72(n/a), 1-8. [2]. https://doi.org/10.1140/epjd/e2017-80329-9

Link to publication record in Ulster University Research Portal

\author{
Published in: \\ European Physical Journal D: Atomic, Molecular, Optical and Plasma Physics
}

Publication Status:

Published (in print/issue): 16/01/2018

DOI:

10.1140/epjd/e2017-80329-9

\section{Document Version}

Author Accepted version

\section{General rights}

Copyright for the publications made accessible via Ulster University's Research Portal is retained by the author(s) and / or other copyright owners and it is a condition of accessing these publications that users recognise and abide by the legal requirements associated with these rights.

\section{Take down policy}

The Research Portal is Ulster University's institutional repository that provides access to Ulster's research outputs. Every effort has been made to ensure that content in the Research Portal does not infringe any person's rights, or applicable UK laws. If you discover content in the Research Portal that you believe breaches copyright or violates any law, please contact pure-support@ulster.ac.uk. 


\title{
Destruction of chemical warfare surrogates using a portable atmospheric pressure plasma jet
}

\author{
Nikola Škoro ${ }^{1}$, Nevena Puač ${ }^{1}$, Suzana Živković ${ }^{2}$, Dijana Krstić-Milošević ${ }^{2}$, Uroš Cvelbar $^{3}$, \\ Gordana Malović ${ }^{1}$, Zoran Lj. Petrović ${ }^{1,4}$ \\ ${ }^{1}$ Institute of Physics Belgrade, University of Belgrade, Pregrevica 118, 11080 Belgrade, \\ Serbia \\ ${ }^{2}$ Institute for Biological Research "Siniša Stanković", University of Belgrade, Bul. despota \\ Stefana 142, Belgrade, 11060, Serbia \\ ${ }^{3}$ Institute Jožef Stefan, Jamova cesta 39, Ljubljana, 1000, Slovenia \\ ${ }^{4}$ Serbian Academy of Sciences and Arts, Knez Mihailova 35, 11000 Belgrade, Serbia \\ E-mail: nskoro@ipb.ac.rs
}

\begin{abstract}
Today's reality is connected with mitigation of threats from the new chemical and biological warfare agents. A novel investigation of cold plasmas in contact with liquids presented in this paper demonstrated that the chemically reactive environment produced by atmospheric pressure plasma jet (APPJ) is potentially capable of rapid destruction of chemical warfare agents in a broad spectrum. The decontamination of three different chemical warfare agent surrogates dissolved in liquid is investigated by using an easily transportable APPJ. The jet is powered by a $\mathrm{kHz}$ signal source connected to a low-voltage DC source and with $\mathrm{He}$ as working gas. The detailed investigation of electrical properties is performed for various plasmas at different distances from the sample. The measurements of plasma properties in-situ are supported by the optical spectrometry measurements, whereas the high performance liquid chromatography (HPLC) measurements before and after the treatment of aqueous solutions of Malathion, Fenitrothion and Dimetyl MetylPhosphonate. These soloutions are used to evaluate destruction and its efficiency for specific neural agent simulants. The particular removal rates are found to be from $56 \%$ up to $96 \%$ during 10 min treatment. The data obtained provide basis to evaluate APPJ's efficiency at different operating conditions. The presented results are promising and could be improved with different operating conditions and optimisation of the decontamination process.
\end{abstract}

\section{Introduction}

The omnipresent threat from the chemical and biological warfare agents have been emphasized in calamitous events of the last decade. In comparison to other weapons of mass destruction, 
the Chemical Warfare $(\mathrm{CW})$ agents are probably one of the most vicious weapons created by mankind given that they are inexpensive and relatively easy to produce, but may result in mass casualties even by using a small agent quantities. Within the efforts to counter this threats, several physical and chemical methods have been developed [1] and successfully employed in CW incidents.

The chemical neutralization methods, depending on the type of the agent, are principally based on hydrolysis and oxidative processes, whereas in a few cases nucleophilic substitution reactions are also employed [1]. However, CW agents present in dilute solutions can undergo an efficient hydrolysis only in the alkaline surroundings, thus an efficient source of $\mathrm{OH}$ radicals is necessary for successful decontamination process. In case of oxidative processes, the crucial limitation for detoxification is presence of sufficient oxidant species with this condition depending on type of the agent and solvent used in particular situation. Nevertheless, several types of chemical decontaminants proved to be efficient source of both species needed for efficient destruction of CW agents [1].

However, chemical methods involve the use of large amounts of chemically hazardous solutions that are dangerous to the environment and require proper storage as well as disposal $[1,2]$. Moreover, these solutions are not adequate for treatment of sensitive surfaces and demand safety installations in facilities for their application. Recently, the raise of novel emerging technologies such as photocatalytic methods and non-equilibrium plasmas is seen as a new promising route to safe decontamination of CW agents [2-4]. One of these technologies is atmospheric pressure plasma based processing, which has proved its usage versatility in many large-scale and industrial applications $[5,6]$. Atmospheric pressure plasma jets (APPJ) demonstrated to be technically simple, but efficient sources of cold atmospheric pressure plasmas suitable for various kind of biological and medical applications. There are numerous reports confirming the efficiency of plasma jets in sterilization and cleaning, i.e. their effect on organic materials and microorganisms [7-11]. Latest direction of research, featuring plasma- 
liquid systems with APPJ, has revealed that chemically reactive environment produced by this type of plasma source is capable of rapid destruction of a broad spectrum of microorganisms, poisonous chemicals and medical drugs [12-16]. Along with these applications, we aim to investigate a possibility of destruction of CW agent surrogates dissolved in liquids by using an APPJ.

So far, several studies investigated decontamination of CW agents (or its surrogates) by using different types of plasma sources [2, 17-19]. However, in these studies treatment target is a coupon spiked with a toxic substance, i.e. treatment is performed over very thin film of the substance. In a lifelike situation of a $\mathrm{CW}$ incident, the contaminated environment surfaces are covered with the film of an agent but the main contaminating activity is through an aerosol. Thus, an efficient decontamination of CW agents dissolved in a liquid phase would mean that agents in a form of aerosol will be destroyed with an even higher efficiency.

The simple decontamination setup for investigation of our proof-of-concept is based on frequently used APPJ with He as working gas and its interaction with the liquid sample surface. The jet operating in the air generates high-energy electrons, reactive oxygen and nitrogen species, $\mathrm{OH}$ radicals, $\mathrm{H}_{2} \mathrm{O}_{2}$ and ultraviolet radiation which is then transferred to the liquid through an interface layer $[20,21]$. The idea is that the reactive oxygen or nitrogen species produced inside the plasma jet and in the interfacial layer then subsequently react with organic molecules and oxidize them [22], which might lead to neutralization of $\mathrm{CW}$ agents. This hypothesis is then tested in this paper on 3 models of CW surrogates and the efficiency of decontamination source is evaluated.

\section{Experimental setup and measurement methods}

Plasma source used in this investigation was atmospheric pressure plasma jet (APPJ) with needle-type electrode. The experimental setup used for treatments of $\mathrm{CW}$ surrogates is presented in Fig.1. The plasma jet Teflon housing (width $26 \mathrm{~mm}$, length $125 \mathrm{~mm}$ ) contains a 
glass tube of $2 \mathrm{~mm}$ inner diameter and $4 \mathrm{~mm}$ outer diameter connected to the gas inlet through a flow regulator. The tube end protrudes shorter side of the housing by $8 \mathrm{~mm}$. For all experiments, the helium (5.0 purity) was used as the feed gas and kept at the constant flow rate of $2 \mathrm{slm}$. The copper wire was placed axially inside the tube acted as a needle-type powered electrode. The electrode was connected through a BNC connector on top of the housing to the $\mathrm{kHz}$ signal provided by a custom made power source. The source itself was packed inside a plastic box $20 \times 12 \times 6 \mathrm{~cm}$ with connection plugs and a switch. It was powered by a low-voltage DC supply providing at the output several kilovolts signal. Output voltage range of the source was dependent on the DC voltage. In experiments an $8 \mathrm{~V}$ DC power supply with maximum current of $400 \mathrm{~mA}$ was used.

Described atmospheric pressure plasma jet can be used as a hand-held device due to the small size. This feature, along with a compact power supply and ability to be powered by low-voltage DC source makes this system highly portable and in perspective enables the opportunity to be employed as a personal protection device.

Samples for treatments were placed in a 24-well microtiter plate underneath the jet. The distance between the end of the jet tube and the liquid surface was fixed at $15 \mathrm{~mm}$ for all sample treatments. In all cases volume of the sample placed into the plate well was $1 \mathrm{ml}$, occupying approximately one half of the well volume.

In order to allow the complete electrical characterization, the copper tape was fixed to the outer side of the well bottom and connected to the ground in a series with a $100 \mathrm{k} \Omega$ resistor. In this way, by measuring voltage drop at this resistor, the discharge current was monitored on the oscilloscope. At the same time, the high-voltage probe connected to the needle electrode connector was displaying driving voltage from the power supply.

In addition to electrical measurements, the optical emission spectrometry during sample treatments was performed. The axis of lens, $5 \mathrm{~mm}$ in diameter and $3 \mathrm{~mm}$ focal length, was placed at the liquid-gas interface level. It was positioned side on, at the distance of $3 \mathrm{~cm}$ from 
the central axes of the jet tube. The lens was collecting and forwarding discharge emission through an optical fiber connected to the entrance of Andor Shamrock 750, $750 \mathrm{~mm}$ focal length Czerny-Turner spectrograph, equipped with an ICCD camera (Andor iStar 734i) as a detector.

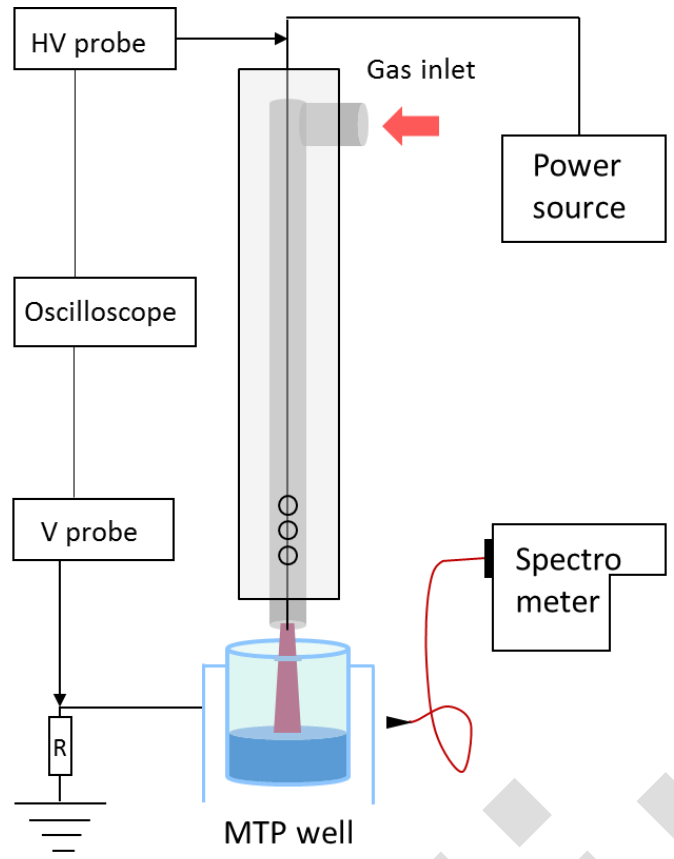

Figure 1 Experimental setup for treatment of liquid samples by APPJ.

Aqueous solutions of three chemical compounds, the surrogates of $\mathrm{CW}$ agents, were used in experiments. As simulant for nerve agent VX we used the organophosphate Malathion (92\% purity, Sigma-Aldrich), as simulant for GD - Fenithrotion (97\% purity, Sigma-Aldrich) [23], while Dimetyl MetylPhosphonate (DMMP) was applied as a GB agent - Sarine surrogate [23]. The solutions in water were prepared just before treatments, whereas the liquid chromatography measurements were conducted after the end of plasma treatment. No excessive heating of the whole sample during treatments was noticed although evaporation of the sample was observed. Additionally, during experiments in a microtiter plate well, the control sample was placed in another well in the vicinity of the experiment, and was exposed to the same room environment (without gas flow above). This way we accounted also for 
evaporation of the sample placed in the open air. After the treatment, the volume of both samples was carefully determined before proceeding to the liquid chromatography measurements

Chromatographic analysis of samples was performed on a Agilent HPLC system, model 1100 with DAD, using Hypersil BDS-C18 (5 $\mu$ l), 125 x 2 mm I.D. column (Phenomenex, USA). The samples were filtered through a $0.2 \mu \mathrm{m}$ cellulose filters (Agilent technologies, Santa Clara, CA, USA) prior to analysis. Acetonitrile (ACN) and 1\% (v/v) solution of ortho-phosphoric acid in water were used as mobile phases. Isocratic elution was performed with details given in Table 1.

Table 1 Details of HPLC measurement methods used for CW agent simulants
Mobile Phase A
Water with $1 \%$ phosphoric acid

Mobile Phase B

Column Temperature

\begin{tabular}{ccccc} 
Sample Injection Volume & & \multicolumn{3}{c}{$10 \mu \mathrm{L}$} \\
\hline & A\% & B\% & Flow rate & Peak detection \\
\hline Malathion & 40 & 60 & $1 \mathrm{~mL} / \mathrm{min}$ & $210 \mathrm{~nm}$ \\
DMMP & 50 & 50 & $0.5 \mathrm{~mL} / \mathrm{min}$ & $210 \mathrm{~nm}$ \\
Fenitrothion & 30 & 70 & $0.4 \mathrm{~mL} / \mathrm{min}$ & $210 \mathrm{~nm}$ \\
\hline
\end{tabular}

\section{Acetonitrile}

$$
25^{\circ} \mathrm{C}
$$

(1)

Solvents for analysis (acetonitrile and ortho-phosphoric acid) were HPLC grade, obtained from Fisher Scientific (Loughborough, UK). Ultrapure water was generated by deionization (Millipore, Billerica, USA). UV detection of the signal was set at $210 \mathrm{~nm}$ for all three chemicals [24]. HP Chemstation chromatographic software (Palo Alto, CA, USA) was employed for data collection.

\section{Results and Discussion}


Plasma treatments of CW agent surrogates by APPJ were conducted for different duration times for all three organophosphate compounds. In order to characterize treatment conditions for every treatment, the optical emissions from the discharges were recorded. In addition, the measurements of voltage and current waveforms for different distances between sample and the jet were also performed.

3.1 Optical emission spectra and electrical characterization of the plasma jet

Optical emission measurements were performed by collecting the light coming from the interface region between the liquid sample and plasma during treatments for all three $\mathrm{CW}$ agent simulants. Since the level of this interface was within the well, approximately at half of the well depth, the plastic well wall prevented transmission of any light below $350 \mathrm{~nm}$. Moreover, at shorter distances most of the plasma was not accessible for optical emission recording due to the microtiter plate covering most of the volume of the plasma while for distances beyond $21 \mathrm{~mm}$ plasma does not reach the liquid. Thus, discharge emission was measured in the wavelength range from $350 \mathrm{~nm}$ to $750 \mathrm{~nm}$ only at $15 \mathrm{~mm}$ distance between the jet and liquid surface - the position used for treatment of CW agent surrogates.

The spectra obtained during treatments of all three chemicals were identical, indicating that the emitting particles were only those from the mixture of surrounding air and He excited in plasma. However, in the recorded spectra above $440 \mathrm{~nm}$ the only line visible was He line at $706.5 \mathrm{~nm}$. In Fig. 2 the limited part of the spectrum of DMMP in the range from $350 \mathrm{~nm}$ to $440 \mathrm{~nm}$ with identified nitrogen molecule lines is presented. The largest number and the strongest lines in this spectral range come from the Second positive system (SPS) of $\mathrm{N}_{2}$. Apart from this emission, the two lines of $\mathrm{N}_{2}{ }^{+}$ionic first negative system (FNS) were also visible. 


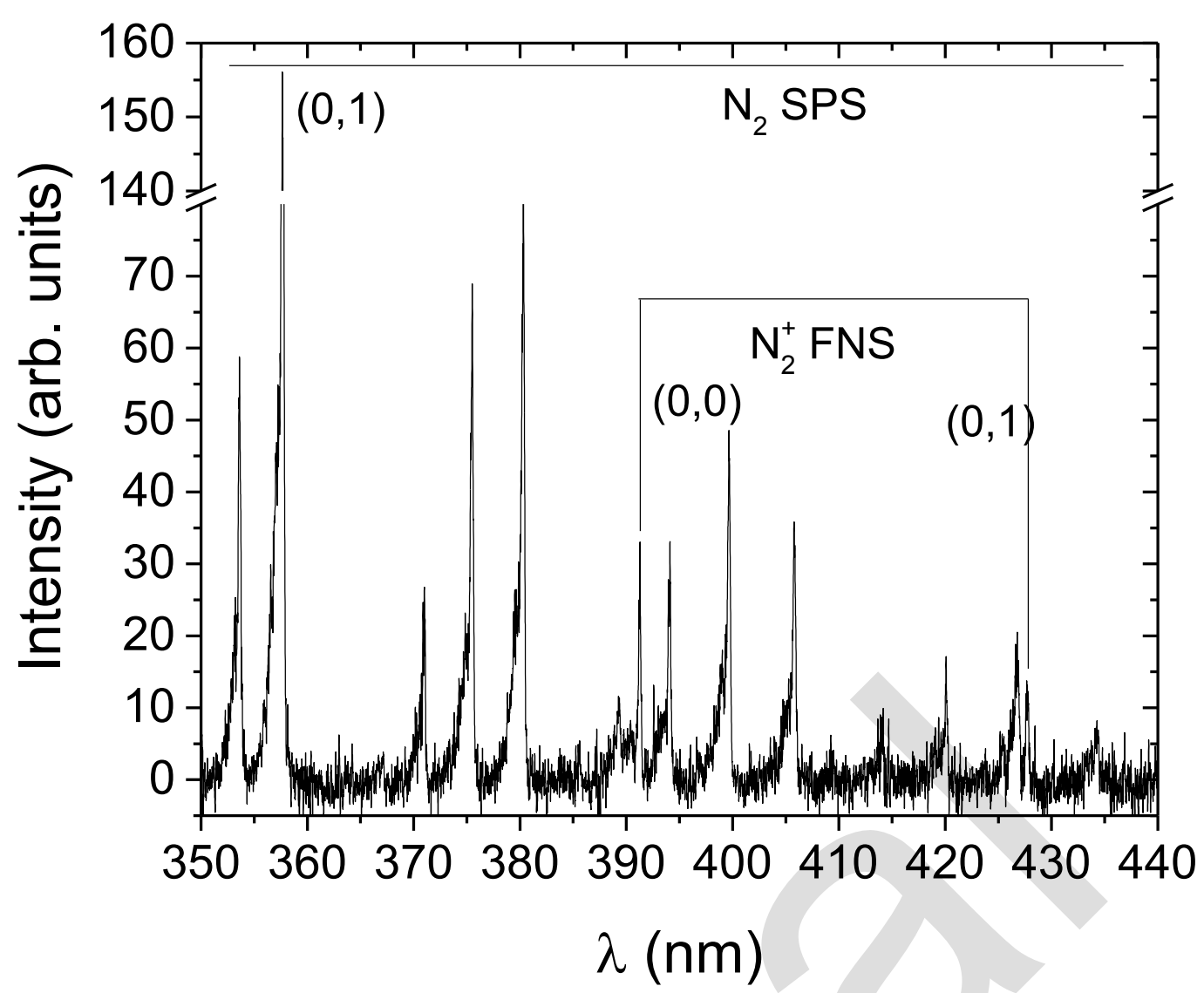

Figure 2 Intensity normalized optical emission from the plasma region directly above the liquid surface for DMMP - CW surrogate at $2 \mathrm{slm}$ of He flow and $15 \mathrm{~mm}$ distance between the jet and liquid surface. Second positive system (SPS) and First negative system (FNS) bands of $\mathrm{N}_{2}$ and $\mathrm{N}_{2}{ }^{+}$are observed.

The observation of both molecular and ionic lines of $\mathrm{N}_{2}$ is known for similar types of APPJs operating in He/air mixture [25-28]. Usually, the $\mathrm{N}_{2}{ }^{+} \mathrm{FNS}(0,0)$ line intensity (at $391 \mathrm{~nm}$ ) is similar or even of stronger than the strongest $\mathrm{N}_{2}$ SPS $(0,0)$ line at $337 \mathrm{~nm}$ (not shown in Fig.1). Nevertheless, in presented case the $391 \mathrm{~nm} \mathrm{~N}_{2}{ }^{+}$line is considerably weaker than the one of the usually lower intensity $\mathrm{N}_{2}$ SPS lines $(358 \mathrm{~nm})$ that correspond to $(0,1)$ transition. Changes in radiative intensities of lines of the plasma jet operating in air or in He/air mixture were observed before, and it was exposed that they depend on the distance of the light collection region from the jet tube end [29-31]. On the other hand, it has also been confirmed that properties of the dielectric target affect intensities of atomic and molecular emission lines and the structure of plasma effluent [32-34]. Since in our case the emission is recorded just above the liquid, away 
from the jet tube, almost certainly both the decrease of excited species concentration along the effluent and the proximity of the liquid target affect the reduction of intensities of the $\mathrm{N}_{2}{ }^{+}$lines. Electrical measurements showed that with the jet position the voltage and current RMS values change. This is observed in Fig.3, where the distance between the jet tube end and the liquid sample surface correlation is plotted. The RMS values are calculated from the waveforms of the driving voltage and the voltage drop measured over the resistor in grounded line. At the shortest distance of $10 \mathrm{~mm}$ end of the jet tube is positioned at the brim level of the well. For distance above $26 \mathrm{~mm}$ it appears from visual observation that plasma plume is not touching surface of the liquid (indicated with dashed line in Fig.3).

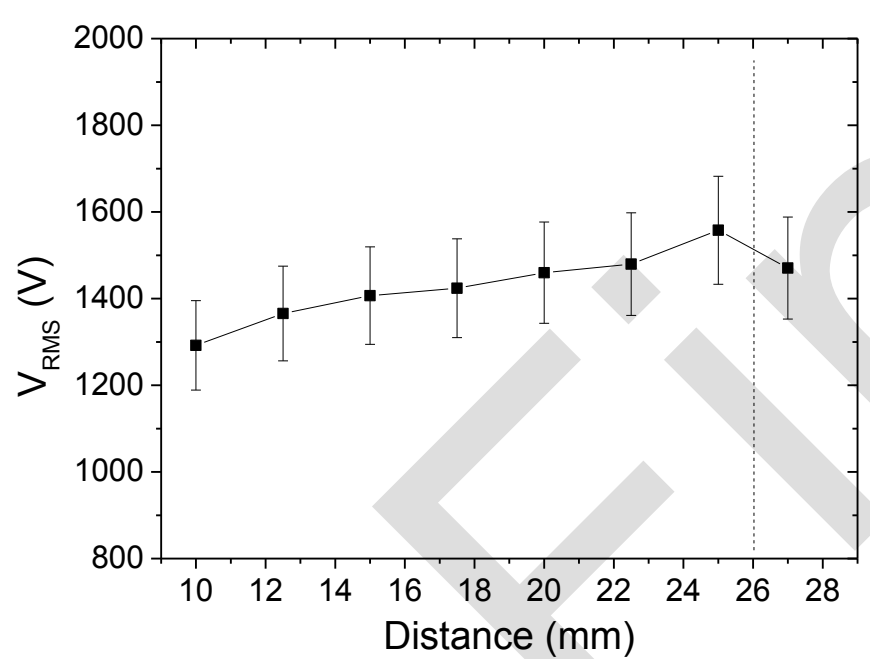

a)

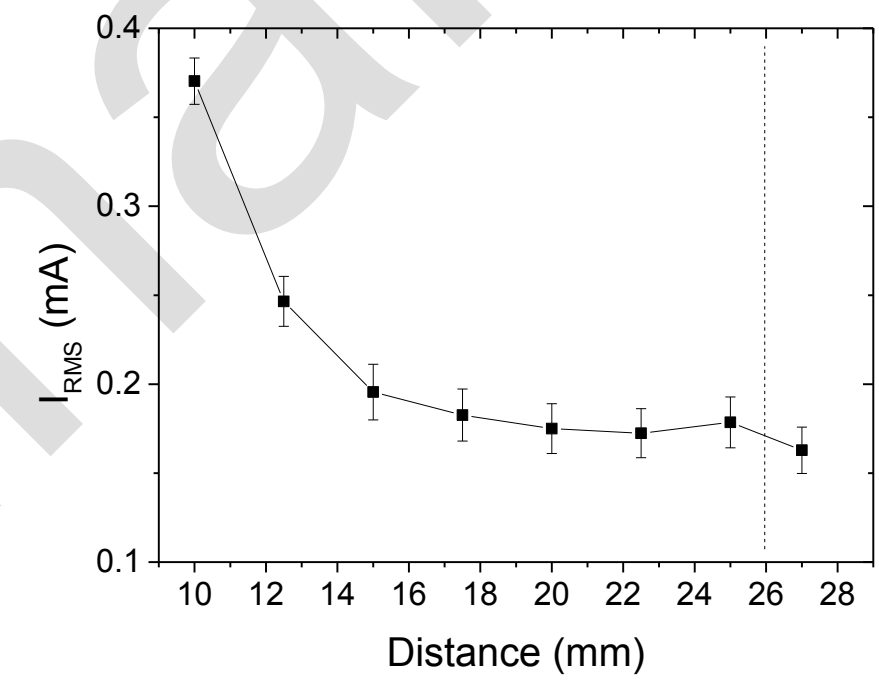

b)

Figure 3 Values of driving voltage (a) and discharge current (b) for different distances between the jet and liquid sample surface.

Voltage RMS values have a steady rise from $1300 \mathrm{~V}$ up to around $1550 \mathrm{~V}$ with the distance increase, as observed in Fig.3(a). At the largest distance, when visually plasma plume is not connected to the liquid surface, the voltage decreases. Current RMS values in Fig.3(b) are significantly reduced with the distance from $10 \mathrm{~mm}$ to $15 \mathrm{~mm}$ and then they stay almost constant at longer distances. Again, similar to $\mathrm{V}_{\mathrm{RMS}}$, there is a small drop in the current when plasma is visually detached from the liquid surface. As it has been shown before, the behavior 
of the plasma in plasma jet systems is influenced by the gas flow, geometrical features of the jet tube, geometry of the electrode system and dielectric properties of the target [35-38]. As distance between the tip of the plasma jet tube and the substrate increases two critical changes will occur. Radial losses will increase with the distance thereby making the measured current smaller and also the abundance of air in the plasma will increase thereby increasing the losses of electrons and reduction of conductivity. Other possible mechanisms could affect the actual selfsustaining field at the tip of the developing streamer and overall distribution of the field but those are much more difficult to predict. Nevertheless in all scenarios an increase of the gap would lead to reduction of the current (provided that the available voltage is limited).

\subsection{Decontamination of CW surrogates}

In order to investigate effectiveness of plasma treatments on degradation of $\mathrm{CW}$ surrogates dissolved in water, the HPLC analysis were performed in the samples before and after the treatments. Quantification in HPLC analysis is based on calibration and calculation procedure that uses area or height of a peak of measured compound to determine its concentration. However, the peaks of CW surrogate degradation products were not identified nor quantified in this study, thus only comparison between the peak areas of the non-treated and treated samples was performed. Nevertheless, using this data we could calculate the decontamination efficiency and subsequently the removal rate as decontamination efficiency in 10 mins treatment. The decontamination efficiency is defined as $\left(\mathrm{C}_{0}-\mathrm{C}\right) / \mathrm{C}_{0}$, where $\mathrm{C}_{0}$ is quantity of an agent surrogate in untreated sample and $\mathrm{C}$ is the residue quantity of the substance. Measurements of control and treated samples obtained in repeated treatments returned almost identical results suggesting stability and repeatability of the plasma treatment.

The HPLC results for $0.1 \%$ solution of Malathion $\left(\mathrm{C}_{10} \mathrm{H}_{19} \mathrm{O}_{6} \mathrm{PS}_{2}\right)$ in water treated for 10 mins and 20 mins are presented in Fig.4. In Fig.4(a), the chromatograms of the control sample (black line) and treated samples (red and green) with two significant peaks are labelled in the plot. All 
chromatograms are normalized to the final sample volume because of evaporation of the solvent. The initial volume of the samples are reduced for $25 \%$ and $30 \%$ after $10 \mathrm{~min}$ and 20 min of treatment, respectively. The peak labelled as Peak 1 corresponds to Malathion while the one labelled as Peak 2 corresponds to its main degradation product Malaoxon [17, 39]. According to manufacturer's specification, other peaks that are visible in the control sample chromatogram belong to impurities.

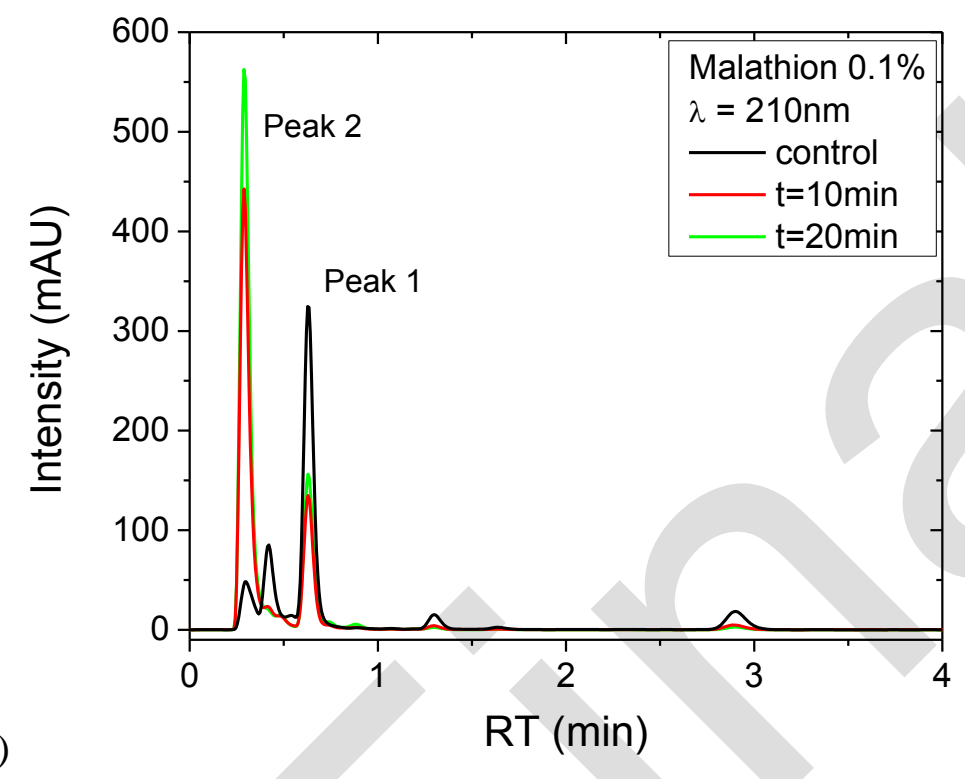

a)

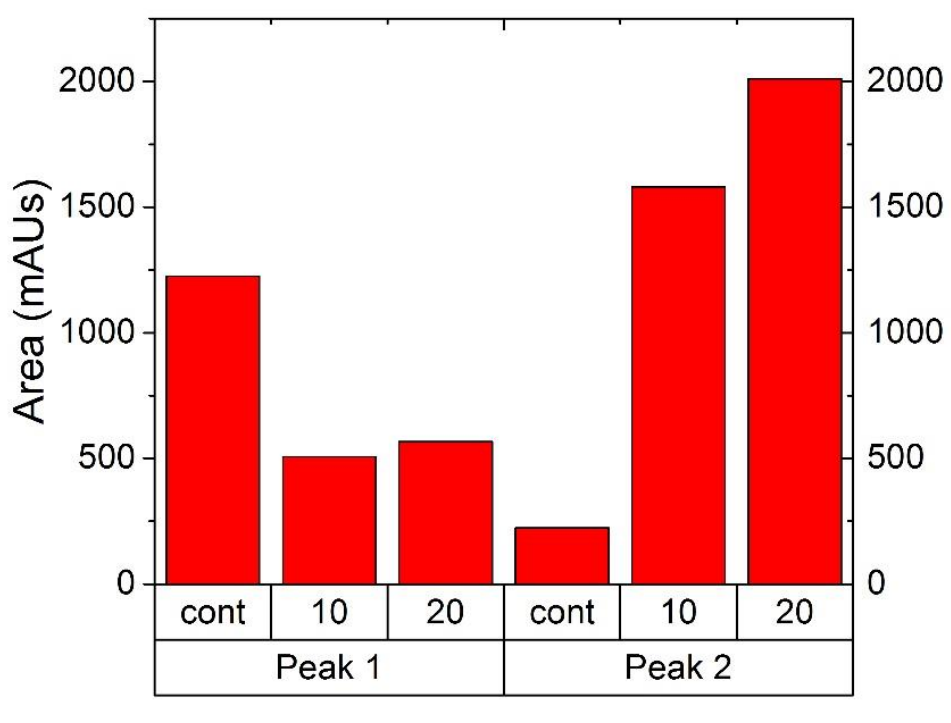

Figure 4 a) Chromatogram of control and treated samples of Malathion. b) Comparison of designated peak areas calculated for control and treated samples. Boxes below bars indicate processing time in minutes. 
The calculated areas of the identified peaks from different samples are compared in Fig.4(b). The treated samples exhibit significant decrease in the concentration of the parent molecule. The area of Peak 1 is reduced for both treatment durations with reduction of around 5 times for treatment of 10 mins. Simultaneously, Peak 2 area of the decomposition product is increased for about 2 and 4 times after treatments of 10 mins and 20 mins, respectively. Taking into account the reduction of Peak 1 area, removal rate of Malathion after 10 mins is $76 \%$.

Peak 1 area of the sample treated for 20 min does not show any further decrease as compared to the area after $10 \mathrm{~min}$ (Fig.4(b)). The lack of further reduction at later times can be attributed to the quenching of the radicals responsible for the destruction due to the higher concentrations of product molecules present in the solution. It has been reported in the literature that the destruction rate of the parent molecule can be decreased with an increase of the treatment time which can be attributed to the quenching of the radicals responsible for the destruction $[40,41]$. The Peak 2 (Fig.4(b)) that represents the decomposition product exists also in the non-treated, control sample. This suggests that Malathion is decomposing in the aqueous solution also unrelated to the plasma treatment. Measurements of the control sample left at room temperature conducted right after making the solution, and after 15 and 30 days of preparation showed that in latter measurements Peak 1 area, corresponding to Malathion, is the same as in the initial measurement. Therefore, the decomposition process which is not induced by plasma occurs immediately after dissolving Malathion in water and then stabilizes, leaving the rest of the parent substance unchanged.

The HPLC measured data for $0.25 \%$ solution of Fenitrothion $\left(\mathrm{C}_{9} \mathrm{H}_{12} \mathrm{NO}_{5} \mathrm{PS}\right)$ in water is presented in Fig.5. After the treatment of 10mins and 20mins the samples have reduced its volumes for $30 \%$ and $50 \%$, respectively, in comparison to the control sample. The volumenormalized chromatograms of the control (black line) sample and samples treated for 10 mins and 20 mins (red and green) with three significant peaks labelled in the plot is shown in Fig. 5(a). Similar to the Malathion sample, the Peak 1 corresponds to the parent molecule, i.e. 
Fenitrothion, while Peak 2 and Peak 3 belong to its main degradation products [42]. Unlike for the Malathion, where peaks in all chromatograms are separate, in treated Fenitrothion samples peaks of degradation products overlap. However, by changing the measurement method parameters with the existing HPLC setup it was not possible to improve separation of the peaks. Therefore, in order to compare peak areas, two Gauss-shaped peaks were deconvoluted from the envelope signal of overlapping peaks which appeared in the retention time (RT) range between $0.4 \mathrm{~min}$ and $0.9 \mathrm{~min}$ for all chromatograms. This example deconvolution is presented in Fig.5(a) for 20 mins treated sample (dashed lines).

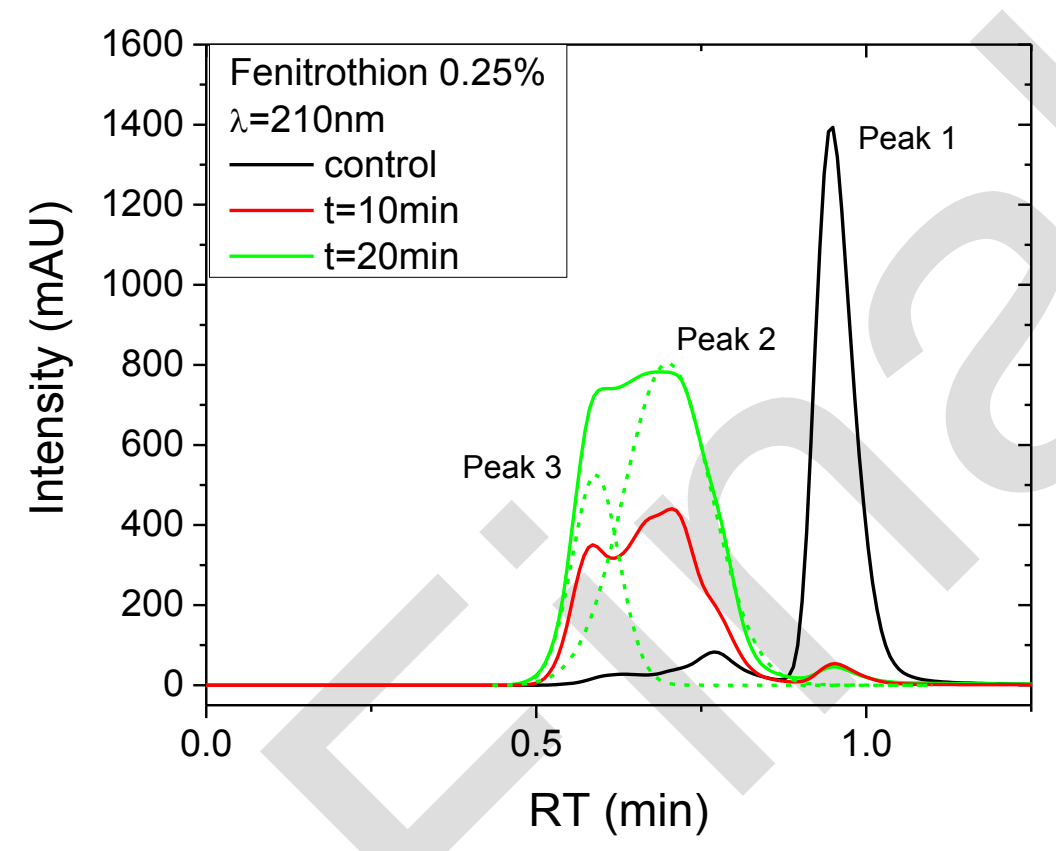

a)

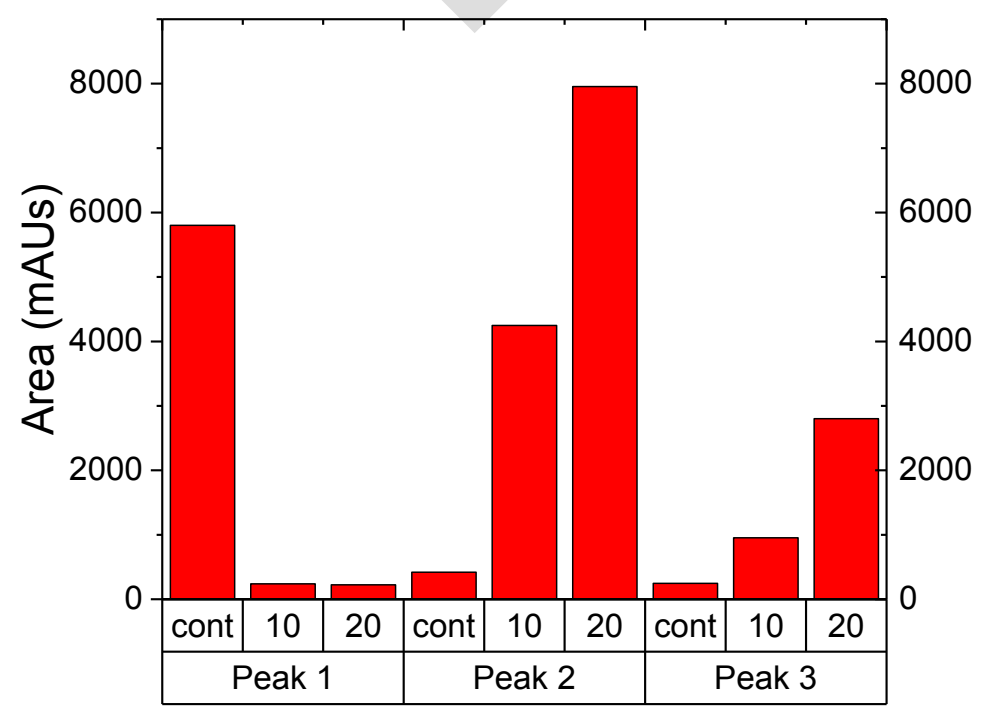


b)

Figure 5 a) Chromatogram of control and treated samples of Fenitrothion. b) Comparison of designated peak areas calculated from control and treated samples. Boxes below bars indicate processing time in minutes.

Comparison of identified peak areas from different chromatograms is exposed in Fig.5(b). After treatment of $10 \mathrm{~min}$, the Peak 1 (parent molecule) almost vanishes with the area from almost 6000 mAUs trimmed down to around 200 mAUs (30 times reduction). Additional 10 mins of treatment causes only minor continuation of agent simulant destruction. Taking into account the reduction of area of Peak 1, the removal rate of Fenitrothion after treatment of 10 mins is $96 \%$. However, both peaks of the decomposition products (Peak 2 and Peak 3) exhibit increase with longer treatment time, displaying that parent molecule and maybe some of the decomposition products continuously degrade during treatment.

The measurements of non-treated and treated samples of 5\% aqueous solution of DMMP $\left(\mathrm{C}_{3} \mathrm{H}_{9} \mathrm{O}_{3} \mathrm{P}\right)$ by HPLC device are revealed in Fig.6. Counter to the previous $\mathrm{CW}$ agent surrogates, volumes of the treated samples are only slightly changed - reduction up to $10 \%$ of the initial volume. The chromatograms normalized to the post-treatment sample volume of the control (black line) sample and samples treated for $10 \mathrm{~min}$ and $20 \mathrm{~min}$ (red and green) are plotted in Fig.6(a) with major peaks labelled. Since the chromatogram of DMMP control sample extends until 4 min of RT, the inset zooms in the range from the starting point up to $\mathrm{RT}=1.3 \mathrm{~min}$, i.e. immediately after detection of the parent molecule peak (Peak 1). All decomposition products (Peak 2-Peak 4) appear in the time before the parent molecule peak. In this case as well, the peaks of decomposition products overlap, so deconvolution of the measured signal by using Gauss-type functions is performed. Following our assumption of 3 major decomposition products [43-45], 4 peaks (including the one of parent molecule) are fitted in the RT range from $0.64 \mathrm{~min}$ to $1.13 \mathrm{~min}$. The fitted functions to the chromatogram of $20 \mathrm{~min}$ treatment (dashed lines) with decomposition product peaks designated by Peak 2 - Peak 4 are presented in the inset of Fig 6(a). 


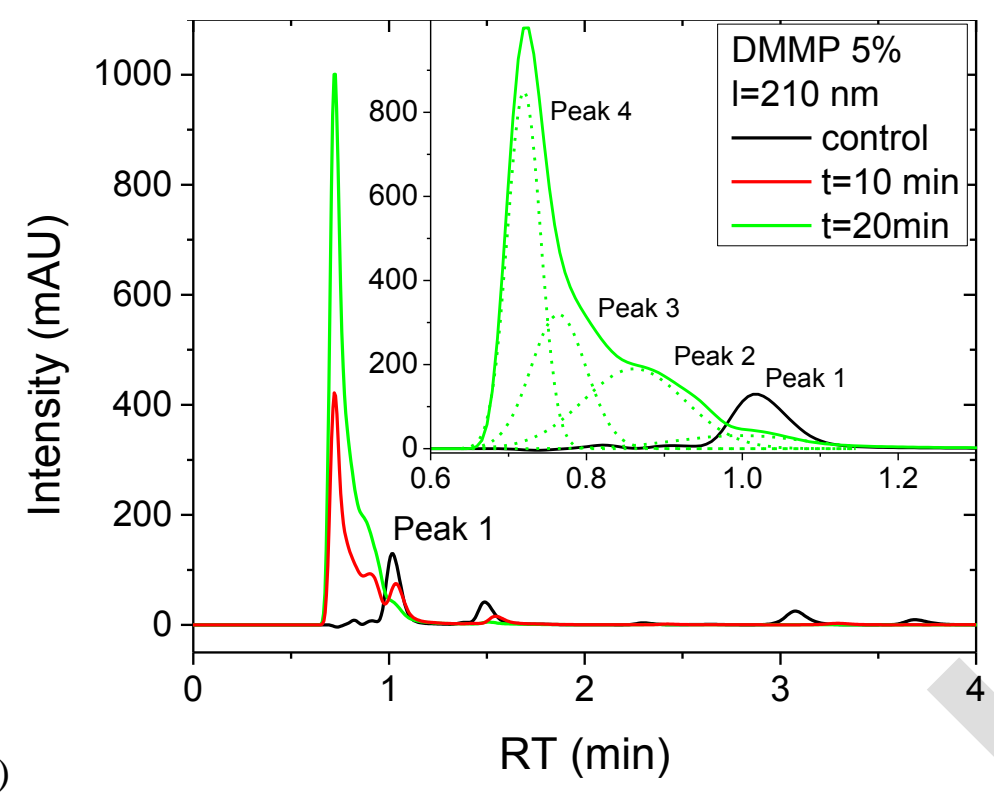

a)

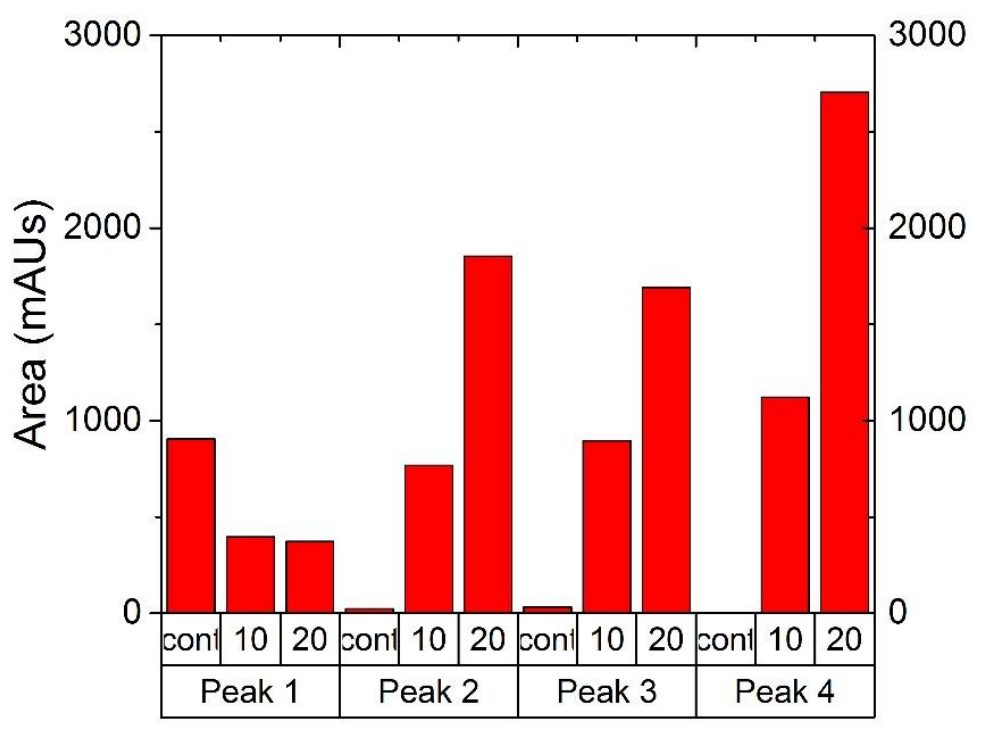

Figure 6 a) Chromatogram of control and treated samples of Dimetyl MetylPhosphonate (DMMP). b) Comparison of designated peak areas calculated from control and treated samples. Boxes below bars indicate processing time in minutes.

Areas of all identified peaks obtained from chromatograms are exposed in Fig.6(b). Practically, the only peak detected in the control sample is the parent molecule Peak 1 with the reduction of the peak area of 2.3 times after 10 min of treatment which results in removal rate of $56 \%$. After 20 min of treatment, the area is reduced 2.4 times compared to the control sample. Nevertheless, peak areas of the decomposition products, which appear after 10 min treatment, 
are significantly higher at the end of the 20 min treatment time, for Peak 2 and Peak $4-2.4$ times higher while Peak 3 is 2 times higher. Therefore, the destruction process obviously persists in the extended time treatments, but further quantitative analysis of decomposition products is necessary for better understanding of destruction mechanisms.

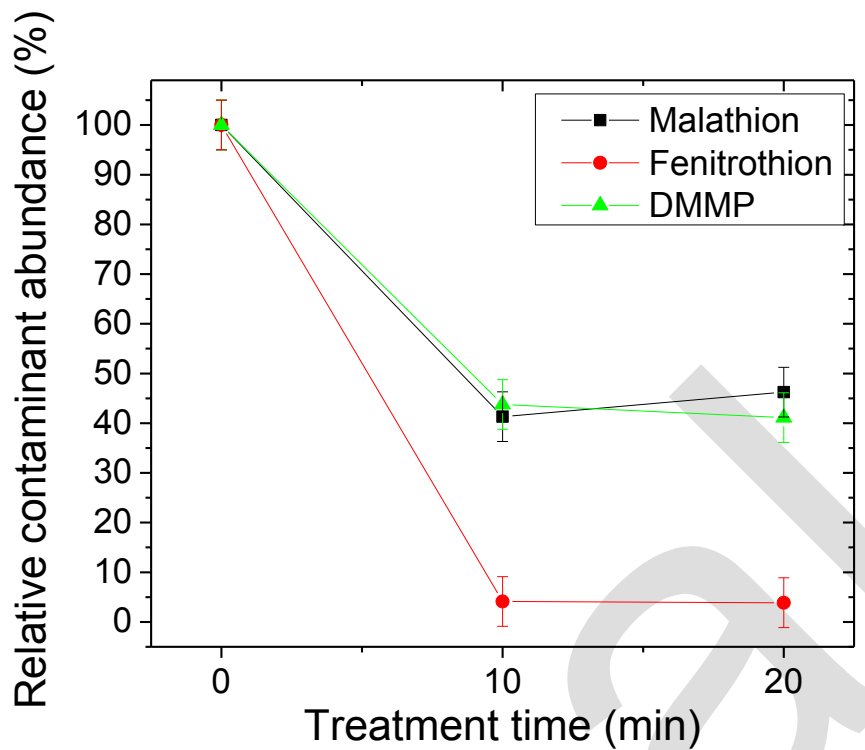

Figure 7. Relative abundance of the target compound (contaminant) as a function of the treatment time. The distance between the plasma jet and liquid target was $15 \mathrm{~mm}$ and helium flow was 2 slm for all three contaminants.

In Figure 7 we show the reduction of the abundance for all three contaminants. We can see that plasma treatment has the highest efficiency in the case of fenitrothion (reduction almost by 100 $\%$ ) while reduction for malation and DMMP are of the order of $60 \%$. Concerning the treatment times, there is no significant difference in contaminant abundance between the $10 \mathrm{~min}$ and 20 min treatments.

\section{Conclusions}

In this paper, a possibility of application of APPJ for decontamination of CW agent surrogates dissolved in water is examined. This approach takes into account the fact that most of the CW 
agents are spread in form of aerosols or liquids, therefore the destruction of the liquid phase $\mathrm{CW}$ is the most important for a successful implementation of decontamination. Recently, the presented models demonstrated that the efficiency of the plasma liquid interactions is higher, when the liquid is in the form of droplets $[46,47]$. That being said, carrying out plasma decontamination in liquid is the most difficult case to perform. Nevertheless, these results also show promise for treatment of droplets and aerosol decontamination that is more difficult to quantify and thus we focused on liquid samples. Before investigation of the decontamination efficiency in liquid samples, the systematic investigation of the electric characteristics of APPJ while treating a liquid sample at different conditions, i.e. distances between the jet and liquid surface was performed. The measurements of voltage RMS values displayed only minor increase with the increasing distance, while the current RMS values drop sharply as the distance increase to $15 \mathrm{~mm}$ and then stay almost constant at longer gaps. Changes in voltage and current are correlated with changes in air/He mixture due to different position between the jet and the microtiter plate. As the first step in the study of the efficiency of decontamination, we examined here the destruction of agents at fixed position of $15 \mathrm{~mm}$ above the liquid surface.

Optical emission spectroscopy of the plasma-liquid interaction volume was also performed. However, the comparison of measured optical emission spectra during treatments of all three agent simulants in the wavelength range from $350 \mathrm{~nm}$ to $750 \mathrm{~nm}$ showed no differences, meaning that observable emission comes only from particles in air/He mixture excited in plasma. Accordingly, the most abundant lines belong to nitrogen molecule species which emit below $440 \mathrm{~nm}$ and one He line at $706.5 \mathrm{~nm}$.

HPLC analysis of liquid samples before and after the treatment confirmed that significant and efficient degradation of all $\mathrm{CW}$ surrogates could be achieved. The destruction of the parent substance is detected on the basis of its peak area reduction and the appearance of new peaks in chromatograms of treated samples. The removal rates of toxic chemicals after $10 \mathrm{~min}$ of treatment ranged from 56\% in case of DMMP (GB agent surrogate), to $76 \%$ for Malathion (VX 
agent) and even $96 \%$ for Fenitrothion (GD agent). Efficient destruction of simulant chemicals exhibits a promise that this kind of cold plasma treatments could be successful for removal of the real $\mathrm{CW}$ agents from surfaces and aerosols by personalized tools.

However, for now the open questions are whether the remaining decomposition products are still harmful and whether these byproducts could be fragmented further by plasma treatment. For instance, in case of Malathion, the main product of destruction is Malaoxon that is also highly toxic. Nevertheless, the precise determination of mass spectra of treated samples would enable identification and characterizations of the decomposition products of $\mathrm{CW}$ agent surrogates as well as their toxicity level. All this data would be valuable for evaluation of APPJ's efficiency at different operating conditions and further optimization of the decontamination process. Recent advances in understanding of the physics and chemistry of the breakdown in liquids $[20,21]$ open new possibilities to optimize removal of contaminants even as dangerous as $\mathrm{CW}$ agents. In general these techniques may be employed for removal of a broad spectrum of contaminants from water supplies.

\section{Acknowledgements}

This work is supported by NATO Science for Peace Multi-Year Project SPS 984555, "Atmospheric pressure plasma jet for neutralization of CBW (chemical biological weapons)", COST TD1208 and projects ON171037 and III41011 of MESTD, Serbia.

\section{Author contribution statement}

U.C. and Z.Lj.P. conceived the idea and supervised the project. U.C. designed the device, N.ŠS., N.P. and S.Ž. performed the experiments and measurements and analyzed the data. D.K.M. supervised and assisted with HPLC measurements, G.M. helped supervise the project. N.Š., N.P. and S.Ž. wrote the manuscript and U.C. and Z.Lj.P. contributed to the final version of the manuscript. 


\section{References}

1. Y. C. Yang, J. A. Baker, J. Richard Ward, Chem. Rev. 92 (8), 1729 (1992)

2. H. W. Herrmann, I. Henins, J. Park, and G. S. Selwyn, Phys. Plasmas 6(5), 2284 (1999)

3. T. Hirakawa, N. Mera, T. Sano, N. Negishi, K. Takeuchi, J. Pharm. Soc Japan 129(1), 71 (2009)

4. C. Bisio, F. Carniato, C. Palumbo, S.L. Safronyuk, M.F. Starodub, A.M. Katsev, L. Marchese, M. Guidotti, Catalysis Today 277, 192 (2016)

5. A. Fridman, A. Chirokov and A. Gutsol, J. Phys. D: Appl. Phys. 38, R1 (2005)

6. C. Tendero, C. Tixier, P. Tristant, J. Desmaison, P. Leprince, Spectrochim. Acta .B 61, 2 (2006)

7. N. Puač, M. Miletić, M. Mojović, A. Popović-Bijelić, D. Vuković, B. Miličić, D.

Maletić, S. Lazović, G. Malović, Z. Lj. Petrović, Open Chemistry 13 (1), 332 (2015)

8. J. L. Zimmermann, T. Shimizu, H. U. Schmidt, Y. F. Li, G. E. Morfill, and G. Isbary, New Journal of Physics 14(7), 073037 (2012)

9. G. Fridman, G. Friedman, A. Gutsol, A. B. Shekhter, V. N. Vasilets and A. Fridman, Plasma Proc. Polymers 5(6), 503 (2008)

10. U. Cvelbar, M. Mozetic, N. Hauptman, M. Klanjsek-Gunde, J. Appl. Phys. 106, 103303 (2009)

11. M. Moisan, J. Barbeau, S. Moreau, J. Pelletier, M. Tabrizian, and L'H. Yahia, Int. J. Pharmaceut. 226, 1 (2001)

12. T. Vukusic, M. Shi, Z. Herceg, S. Rogers, P. Estifaee, S. M. Thagard, Innovative Food Science and Emerging Technologies 38, 407 (2016)

13. M. Magureanu, N. B. Mandache, V. I. Parvulescu, Water Res. 81, 124 (2015)

14. E.J. Klimova, F. Krcma, L. Jonisova, EPJ Applied Physics 75 (2) 24709 (2016)

15. S. Krishna, E. Ceriani, E. Marotta, A. Giardina, P. Špatenka, C. Paradisi, Chemical Engineering Journal 292, 35 (2016) 
16. John E. Foster, Phys. Plasmas 24, 055501 (2017)

17. Z. Wen-Chao, W. Bai-Rong, X. Hai-Ling, P. Yi-Kang, Plasma Chem Plasma Process 30, $381(2010)$

18. Z. Li, Y. Li, P. Cao, H. Zhao, Plasma Sci. Tech. 15, 696 (2013)

19. H. W. Herrmann, G. S. Selwyn, I. Henins, J. Park, M. Jeffery, and J. M. Williams, IEEE Trans. Plasma Sci. 30(4), 1460 (2002)

20. P J Bruggeman, M J Kushner, B R Locke, J G E Gardeniers, W G Graham, D B Graves, R C H M Hofman-Caris, D Maric, J P Reid, E Ceriani, D Fernandez Rivas, J E Foster, S C Garrick, Y Gorbanev, S Hamaguchi, F Iza, H Jablonowski, E Klimova, J Kolb, F Krcma, P Lukes, Z Machala, I Marinov, D Mariotti, S Mededovic Thagard, D Minakata, E C Neyts, J Pawlat, Z Lj Petrovic, R Pflieger, S Reuter, D C Schram, S Schroeter, M Shiraiwa, B Tarabová, P A Tsai, J R R Verlet, T von Woedtke, K R Wilson, K Yasui and G Zvereva, Plasma Sources Sci. Technol. 25, 053002 (2016)

21. I. Adamovich, S. Baalrud, A. Bogaerts, P. J. Bruggeman, M. Cappelli, V. Colombo, U. Czarnetzki, U. Ebert, J. G. Eden, P. Favia, D. B. Graves, S. Hamaguchi, G. Hieftje, M. Hori1, I. D. Kaganovich, U. Kortshagen, M. J. Kushner, N. J. Mason, S. Mazouffre, S. Mededovic Thagard, H.-R. Metelmann, A. Mizuno, E. Moreau, A. B. Murphy, B. A. Niemira, G. S. Oehrlein, Z. Lj. Petrovic, L. C. Pitchford, Y.-K. Pu, S. Rauf, O. Sakai, S. Samukawa, S. Starikovskaia, J. Tennyson, K. Terashima, M. M. Turner, M. C. M. van de Sanden, A. Vardelle J. Phys. D: Appl. Phys. submitted (2017)

22. M. M. Hefny, C. Pattyn, P. Lukes, J. Benedikt, J. Phys D: App. Phys. 49, 404002 (2016)

23. S. L. Bartelt-Hunt, D. R. U. Knappe, M. A. Barlaz, Environmental Science and Technology 38, 112 (2008)

24. R. T. Rewick, M. L. Schumacher, and D. L. Haynes, Appl. Spectr. 40, 152 (1986) 
25. E. Nwankire, V. J. Law, A. Nindrayog, B. Twomey, K. Niemi, V.Milosavljević, W. G.

Graham, and D. P. Dowling, Plasma Chem. Plasma Process. 30, 537 (2010)

26. J. Benedikt, S. Hofmann, N. Knake, H. Boettner, R. Reuter, A. von Keudell, and V.

Schulz-von der Gathen, Eur. Phys. J. D 60, 539 (2010)

27. Y. S. Seo, A.-A. H. Mohamed, K. C. Woo, H. W. Lee, J. K. Lee, and K. T. Kim, IEEE Trans. Plasma Sci. 38, 2954 (2010)

28. R. Brandenburg, J. Ehlbeck, M. Stieber, T.v.Woedtke, J. Zeymer, O. Schlueter, and K.D.Weltmann, Contrib. Plasma Phys. 47, 72 (2007)

29. A. N. Korbut, V. A. Kelman, Yu. V. Zhmenyak, and M. S. Klenovskii, Optics and Spectroscopy 116, 919 (2014)

30. E. Ilik and T. Akan, Phys. Plasmas 23, 053501 (2016)

31. G. V. Naidis, Plasma Sources Sci. Technol. 23, 065014 (2014)

32. A. V. Nastuta, V. Pohoata, and I. Topala, J. Appl. Phys. 113, 183302 (2013)

33. S. Hofmann, K. v. Gils, S. v. d. Linden, S. Iseni, and P. Bruggeman, Eur. Phys. J. D 68, $56(2014)$

34. X. Damany, S. Pasquiersa, N. Blin-Simiand, G. Bauville, B. Bournonville, M. Fleury, P. Jeanney, and J. S. Sousa, Eur. Phys. J. Appl. Phys. 75, 24713 (2016)

35. N. Puač, D. Maletić, S. Lazović, G. Malović, A. Đorđević, Z. Lj. Petrović, Appl. Phys. Lett. 101, 024103 (2012)

36. D. Maletić, N. Puač, N. Selaković, S. Lazović, G. Malović, A. Đorđević and Z.Lj. Petrović, Plasma Sources Sci. Technol. 24, 025006 (2015)

37. E Robert, V Sarron, T Darny, D Ries, S Dozias, J Fontane, L Joly and J-M Pouvesle, Plasma Sources Sci. Technol. 23, 012003 (2014)

38. S. Hofmann, K. van Gils, S. van der Linden, S. Iseni, and P. Bruggeman, Eur. Phys. J. D 68, 56 (2014)

39. A.W. Abu-Qare, M.B. Abou-Donia, J. Pharm. Biomed. Anal. 26, 291 (2001) 
40. B. Jiang, J. Zheng, S. Qiu, M. Wu, Q. Zhang, Z. Yan, and Q. Xue, Chem. Eng. J 236, $348(2014)$

41. M. Hijosa-Valsero, R. Molina, A. Montràs, M. Müller, and J.M. Bayona, Environ. Tech. Rev. 3, 71 (2014)

42. P. Kuklenyik, Ph.D. thesis, Georgia State University, 2009

43. H. Ando, Y. Miyata, in Drugs and Poisons in Humans, edited by O. Suzuki and K. Watanabe (Springer-Verlag Berlin Heidelberg New York, 2005)

44. S. C. Cho, H. S. Uhm, Y. C. Hong, Y. G. Park, and J. S. Park, J. Appl. Phys. 103, $123303(2008)$

45. T.Z. Tzou and S. W. Weller, Journal of Catalysis 146, 370 (1994)

46. J. Kruszelnicki, A.M. Lietz and M. J. Kushner, in Proceedings of Intern. Conf. on Plasmas with Liquids-ICPL 2017, Prague, 2017, edited by P. Lukes and K. Kolacek, (IPP CAS, Prague, 2017), p. 371

47. W. Tian, A.M. Lietz and M. J. Kushner, Plasma Sources Sci. Tech 25, 055020 (2016) 